\title{
La obra sociológica del profesor Álvaro Camacho Guizado (1939-2011). Presentación e interpretación
}

Este ensayo pretende llevar a cabo una presentación de la obra y las orientaciones intelectuales del sociólogo Álvaro Camacho Guizado, profesor de varias universidades colombianas entre 1972 y su muerte en 2011 (Universidad del Valle, Universidad Nacional de Colombia y Universidad de los Andes). El ensayo hace énfasis no solo en las características personales del profesor, sino también en su concepción del trabajo del sociólogo y de la sociología como disciplina cuyo carácter crítico proviene precisamente de su dimensión empírica como "artesanía intelectual".

\section{La obra}

La Universidad del Valle y la Universidad de los Andes se han reunido para ofrecer a la comunidad académica la recopilación de la obra del profesor Álvaro Camacho Guizado, miembro de estas instituciones en diferentes momentos de su vida, fallecido en Bogotá el 11 de diciembre de 2011 a la edad de 72 años. El criterio de selección ha sido recuperar todos aquellos trabajos que siguen siendo actuales por su contenido, pero igualmente aquellos textos que tienen valor de documento para comprender la trayectoria y la mentalidad de un intelectual contemporáneo, así como la evolución de la sociología en Colombia.

La obra se ha dividido en cuatro volúmenes que abarcan los principales temas de interés de la investigación sociológica de Camacho: el análisis de coyuntura y estructura, social y política (II); la violencia y el conflicto (III); el narcotráfico (IV); y, como ocurre con frecuencia en un trabajo de recopilación, uno de los volúmenes, en este caso el primero de la serie, recoge textos diversos que no se pueden clasificar en los tres campos anteriores, pero que tampoco conforman un corpus suficiente para organizar un volumen especial. Este bloque, a pesar de su diversidad, nos permite comprender su concepción de la sociología, nos muestra las primeras etapas de su producción intelectual y su interés episódico por el estudio del trabajo informal. La gran mayoría de los ensayos que lo componen fueron escritos antes de 1990.

Para presentar cada uno de los volúmenes se ha solicitado a una persona conocedora del tema, y próxima al autor por un nexo profesional y afectivo, la organización de los textos, la supresión de algunas repeticiones y la elaboración 
de un prólogo que permita al lector ponerse en contacto con el conjunto de cada parte de la obra. Las exclusiones han sido pocas y lo que se ofrece aquí es una recopilación casi completa de sus escritos en un lapso de cincuenta años, desde 1963 hasta el momento de su muerte.

La recopilación comprende tres libros de su propia autoría, un libro escrito a cuatro manos en colaboración con Álvaro Guzmán, la participación en varias obras colectivas y numerosos ensayos. En términos generales la obra tiene un carácter predominantemente ensayístico, hasta el punto de que su libro sobre las drogas es más una colección de ensayos que un tratado sobre el tema. Y desde este punto de vista, se convierte entonces en uno de los mejores representantes en Colombia del "ensayo académico", como un genero particular sometido a las normas de la sistematicidad y del rigor.

En lugar de una presentación estrictamente temporal de los textos, se ha optado por combinar el criterio temático con el criterio cronológico, de manera variable en cada una de sus partes y separando los ensayos de los libros. Esto no impide que el lector que haga el recorrido por los cuatro volúmenes tenga la posibilidad de reconstruir los principales hitos de su trayectoria intelectual, identificar sus características, los cambios de temática e, incluso, de orientación.

En los primeros textos encontramos la huella de un investigador formado en una sociología de orientación empírica, que recorre el país recién graduado en la Universidad para estudiar las instituciones jurídicas en la Guajira o las primeras formas de la colonización del Putumayo. Pero también encontramos a un intelectual marxista altamente politizado en el ambiente de los años 1970. El libro Capital extranjero subdesarrollo colombiano, y la obra compartida con Humberto Rojas Frente Nacional: ideología y realidad, en la que aparece un ensayo sobre este pacto político, lo hicieron conocer ampliamente en el mundo de la izquierda de aquella época. La inspiración marxista también se expresa claramente en su tesis de doctorado de Wisconsin La organización de la centralización del capital en Colombia publicada en 1975 por la Universidad del Valle, en su estudio Ideologías y desarrollo en el Valle del Cauca en la segunda mitad del siglo XIX, y en las investigaciones sobre el trabajo informal elaborados durante la primera mitad de los años 1980, en un momento en que este problema había pasado a un primer plano en el ámbito latinoamericano. A medida que vamos avanzando en su obra las categorías propiamente marxistas utilizadas en sus primeros trabajos (clase, ideología, composición orgánica del capital, renta de la tierra y muchas otras) se van desvaneciendo, pero en ningún momento desaparece el espíritu crítico radical aprendido en la escuela del pensador alemán.

El tema del narcotráfico se convierte en un interés prioritario de sus investigaciones desde finales de la década de 1970. En 1981 la Universidad del Valle publica el libro Droga corrupción y poder: marihuana y cocaína en la sociedad colombiana, que es ampliado y sustituido en 1988 por el libro Droga y sociedad en Colombia: el estigma y el poder. Durante los últimos años de su vida mantiene en la Universidad de los Andes un curso sobre sociología del narcotráfico y en 2011 publica el último de sus artículos sobre este tema. El interés por el análisis de la coyuntura social y política aparece en su producción intelectual desde la década de 1980. A raíz del fracaso de las negociaciones de paz del gobierno de Belisario Betancur y motivado en ese momento por el incidente de la toma por 
parte del Ejército en Cali de la "loma de Mónaco" donde él vivía, como reacción a la presencia del M-19 en el vecino barrio de Siloé, se interesa de manera creciente por el problema de la violencia y el conflicto. Alrededor de estos tres ejes gira su trabajo intelectual durante las últimas tres décadas de su vida. El lector podrá encontrar en esta recopilación de la obra la huella de cada una de estas orientaciones de su investigación.

\section{El intelectual}

Camacho era un hombre que asumía plenamente su identidad como sociólogo, defendía con ahínco la profesión, luchaba por su desarrollo en el país y por su institucionalización en los programas académicos universitarios o en centros de investigación. No obstante, la principal preocupación que daba unidad a su trabajo intelectual no era la sociología a secas, sino el análisis empírico de la sociedad colombiana. La teoría sociológica siempre estuvo en el centro de sus preocupaciones intelectuales pero no como fin en sí misma, en un sentido escolástico o intelectualista, sino como un instrumento al servicio de sus problemas concretos de investigación, bajo la idea de que la teoría solo "se realiza" en el trabajo empírico. De hecho, en el conjunto de su obra encontramos muy pocos ensayos teóricos porque la inmensa mayoría versa sobre análisis de situaciones concretas en los que la teoría aparece siempre integrada al trabajo empírico.

Como aparece en frase marginal en boca de una de las personas que después de su muerte dieron testimonio de su relación con él, se podría decir que Camacho era un "pensador desde lo concreto". Su gran lección consistía en la exigencia de mantener siempre contacto con la realidad: un "polo a tierra" muy bien instalado; en no separar lo teórico de lo empírico, en tener siempre en cuenta que los planteamientos abstractos solo tienen sentido si pueden servir como punto de referencia para acercarse al análisis de una realidad concreta. Tenía una especial sensibilidad para captar la singularidad de todo lo que observaba e, incluso, una dificultad correlativa para remontarse a ideas abstractas sin vínculo con consideraciones empíricas. Esta "exigencia de concreción" es la impronta que dejó en el grupo del Departamento de Ciencias Sociales de la Universidad del Valle durante los 18 años de su permanencia y que aún se conserva.

Un trabajo intelectual de esta naturaleza se construye siempre sobre el trasfondo de unos presupuestos éticos y políticos, que combinan la influencia marxista con una fuerte convicción democrática. Nos encontramos frente a un hombre profundamente convencido de la importancia de los valores democráticos pero, al mismo tiempo, bajo la influencia de Marx, comprometido en un proceso de transformación orientado a construir una sociedad más igualitaria, participativa, sin privilegios y fundada en un poder legítimo y racional (a la manera de Max Weber), sin autoritarismos, sin despotismos, ni arbitrariedades. Sus estudiantes lo recuerdan hablando no solo de Marx sino también de la importancia de Rousseau y Montesquieu, y de las virtudes de la democracia como sistema político. De hecho, una de sus principales orientaciones vitales e intelectuales era el enfrentamiento con el poder, que sometía a la más dura crítica y era objeto de todo tipo de ironías y de sarcasmos. Creía profundamente en la política y se 
oponía a cualquier tipo de violencia, independientemente de donde proviniera, sobre todo a la lucha armada como forma de conquistar el poder.

$\mathrm{Su}$ actitud iconoclasta, inconforme y rebelde frente al poder y la autoridad lo llevaba a convertir en caricatura a todo aquel que pretendiera identificarse, afirmarse o expresarse desde una posición de poder. La idea de inclinarse frente al poderoso le era ajena, llámese decano, rector de Universidad, Presidente de la República o jefe de un grupo armado. Cuando ingresó a la Universidad del Valle en 1972, en un momento en que estaba a la orden del día la expulsión de los profesores de izquierda después de la gran crisis estudiantil de la época, tuvo el valor suficiente para enfrentarse solo, aún a riesgo de su estabilidad laboral, al despotismo de los rectores de turno, porque sus compañeros de entonces habían tenido que salir de la institución.

Camacho era un gran defensor de la política pero era un gran enemigo de las componendas y de todas las formas clientelistas y patrimoniales de apropiación del poder. Una de las principales lecciones que aprendíamos en contacto con él era el respeto por lo público, como se expresa en su empeño por afirmar la importancia de la Universidad, como una de las instituciones básicas de una sociedad democrática. Fue un académico en el pleno sentido de la palabra, que defendía a toda costa la libertad de pensamiento y de expresión como condición fundamental para el desarrollo de la investigación y la docencia. Pero, sobre todo, fue una persona que marcó un estilo de trabajo y una ética, que ponía la actividad académica por encima de cualquier tipo de interés de índole personal y nos invitaba a todos los que éramos sus colegas en ese momento a identificarnos con los intereses colectivos del grupo y de la Universidad, a "ponernos la camiseta del Departamento", como decíamos entonces.

Camacho fue un intelectual que a través de sus actos o de sus ideas tuvo una influencia en la vida política de este país, inspirado por una ética aprendida muy tempranamente en la obra de Wright Mills, uno de sus principales inspiradores, que prescribe vivir los problemas personales como públicos y los públicos como privados. Participó en tres de las principales comisiones que han dejado informes sobre la situación de violencia en el país, que tuvieron una alta incidencia en su momento. Durante la Violencia (con mayúscula) ayudó a sus entonces maestros de la Universidad Nacional a recoger las distintas versiones sobre lo sucedido, como da testimonio la foto suya que aparece en la segunda edición del libro La Violencia en Colombia de monseñor Guzmán y otros. En 1987 hizo parte del conocido grupo de los "violentólogos", que publicaron el libro Colombia: violencia y democracia. Las dos ideas básicas que se difunden en la opinión como resultado del trabajo de la comisión que redactó esta obra, es decir, la existencia de múltiples violencias (no solo la violencia política) y la creciente urbanización del conflicto, se deben en buena medida a su aporte, según el testimonio de sus colegas en esta labor. Y recientemente tuvo una muy activa participación en el Grupo de Memoria Histórica organizado por la Comisión Nacional de Reparación y Reconciliación en el año 2005, donde fue el redactor del primero de los informes Trujillo: una tragedia que no cesa, publicado en el año 2008.

En sus estudios sobre el narcotráfico fue uno de los primeros en mostrar las consecuencias terribles de la política de prohibición de las drogas y en establecer los parámetros de una lucha por la despenalización. Hoy en día es posible 
suponer que su nombre figure en los archivos de la DEA como uno de los intelectuales latinoamericanos más empeñados en hacer oposición a la política antidrogas de los Estados Unidos. Igualmente fue uno de los primeros que se interesó por la figura de las víctimas, no solo de la violencia sino también del narcotráfico en su conjunto, es decir, incluyendo los productores, los campesinos y los consumidores. Uno de sus últimos proyectos intelectuales fue construir una base de datos de las víctimas del narcotráfico durante las últimas décadas. Participó activamente en la reforma de la policía, fue consejero de seguridad ciudadana del alcalde Antanas Mockus de Bogotá y durante varios años mantuvo una columna en el periódico El Espectador, en la cual aparecen de manera recurrente todas estas preocupaciones.

Hay que tener en cuenta que su paso por las instituciones dejó huellas profundas por la cantidad de iniciativas que promovió en su incansable y febril actividad. Camacho no era solo un investigador sino también un hombre de realizaciones, un gran promotor de la creación de grupos para trabajar colectivamente en pro de un proyecto intelectual y de espacios institucionales que lo hicieran posible, con base en un gran poder de convocatoria. Siempre tenía una idea en la cabeza que quería poner en práctica. Durante los años pasados en la Universidad del Valle entre 1972 y 1990 se convirtió en el principal impulsor de la creación de los programas de pregrado y maestría en sociología, del CIDSE (el Centro de Investigaciones de la Facultad de Ciencias Sociales y Económicas), de los coloquios de sociología que ya van en su versión número doce pero, sobre todo, del grupo de trabajo del Departamento de Ciencias Sociales, que aún guarda la huella de su memoria y se rige por principios éticos y académicos que deben mucho a su influencia. De regreso a Bogotá se convierte en un importante impulsor del Instituto de Estudios Políticos y Relaciones Internacionales, el IEPRI de la Universidad Nacional, recién creado en el momento de su ingreso y del cual llegó a ser director; y del Centro de Estudios Socioculturales (CESO) de la Universidad de los Andes, del que también fue director y donde contribuyó desde su posición a su fortalecimiento y a la promoción de una sólida política de publicaciones. Su gran capacidad de trabajar en equipo se expresa en el hecho de que muchos de sus trabajos intelectuales son realizados en colaboración con otras personas.

\section{La sociología como subversión}

Camacho proviene de una tradición crítica de la intelectualidad colombiana, muy marcada en su primera etapa por el marxismo y por la urgencia de una militancia política, orientada a participar en un gran "proceso de transformación revolucionaria de la sociedad". De hecho, en una primera parte de su vida intentó hacer parte de diversos grupos políticos como es el caso del Bloque Socialista (trotskista) o del movimiento Firmes. Un compromiso de esta naturaleza implicaba hacer proselitismo en los barrios populares, escribir comunicados y todo tipo de documentos, contribuir a la creación de un partido político y participar en debates públicos en los que se confrontaban las líneas políticas.

Sin embargo, por razones diversas, Camacho rápidamente comprende que su papel como "intelectual revolucionario" no estaba propiamente en la participación en un grupo político, sino en un compromiso de otro tipo, igualmente vinculado 
con un proceso de transformación de la sociedad, pero probablemente más eficaz y más profundo. Y ese compromiso era el vínculo con la sociología y, más en particular, con el análisis empírico de la sociedad colombiana. En pocas palabras, como se trasluce en la lectura de los textos que aparecen recopilados en la Obra selecta, el compromiso con esta disciplina pasa a sustituir el compromiso revolucionario, como una mejor realización de los mismos ideales de transformación social.

La idea básica es que la sociología, como lo expone en uno de los textos que aparecen en esta recopilación ${ }^{1}$, es una actividad subversiva del orden social, en el mejor sentido de la palabra. Subversión no significa aquí arrojar bombas, tomar las armas, pertenecer a un grupo clandestino, hacer "proselitismo entre las masas" contra el sistema, sino simplemente contribuir con un trabajo teórico y empírico, paciente y riguroso, a la comprensión de una determinada situación, con base en la idea de que la comprensión es un momento fundamental de la transformación de la realidad que se estudia. Impulsar una nueva forma de mirar nuestra sociedad es ya una propuesta de subversión, que va más allá de la definición ordinaria de esta palabra.

Camacho era un duro crítico de ciertas corrientes sociológicas, como es el caso del funcionalismo norteamericano, que conoce ampliamente a su paso por los Estados Unidos, y sobre el cual afirma que "había perdido su capacidad crítica" y la posibilidad de plantear "perspectivas intelectuales orientadoras de acciones transformadoras del orden social". Los aparatos propios de la estructura de poder como las universidades, el Estado o los organismos privados de investigación habían logrado convertir, según su opinión, la "práctica sociológica en una apología del modo de vida norteamericano", al servicio de los intereses de ese país en el mundo².

No obstante este mismo funcionalismo, tan justamente criticado, que proponía un tipo de teorización que podríamos denominar "metafísica" y apologética, había producido también una enorme inspiración empírica como se puede observar en el importante cúmulo de investigaciones que suscitó y que se pueden encontrar en el trabajo de campo de los antropólogos o en la propia sociología norteamericana ${ }^{3}$. Y es de hecho con esta dimensión empírica, y no solo con sus "aspectos metafísicos", con la que Camacho se pone en relación a su paso por los Estados Unidos. Además, una experiencia similar la había vivido en el marco de la Facultad de Sociología de la Universidad Nacional ya que buena parte de los trabajos fundadores de la sociología colombiana, realizados por sus primeros maestros, estaban inspirados por esta misma orientación empírica del funcionalismo, como es el caso de Campesinos de los Andes y El hombre y la tierra en

1 «El oficio del sociólogo. Promesas y compromisos. Discurso de despedida del Departamento de Ciencias Sociales de la Universidad del Valle». En Obra selecta, Volumen I: Academia y sociedad, Álvaro Camacho, 55-66. Bogotá-Cali: Universidad de los Andes, Universidad del Valle, 2014. En este artículo es donde mejor expone de manera explícita su concepción de la sociología y del trabajo del sociólogo, que aparece implícita en toda su obra.

2 'Introducción al libro Perspectivas sociológicas internacionales', en Camacho (2014, 97-101).

3 A juicio de Anthony Giddens "el funcionalismo ha tenido suma importancia en las ciencias sociales no solo por su envergadura como tipo de teorización sino también por la investigación empírica que produjo", aún teniendo en cuenta que "conceptualmente su influjo ha sido en buena parte pernicioso". La constitución de la realidad. Bases para la teoría de la estructuración. Buenos Aires: Amorrortu editores, 1998, p. 31. 
Boyacá, de Orlando Fals Borda, La Violencia en Colombia de monseñor Guzmán (et al.), y La familia en Colombia, de Virginia Gutiérrez.

De hecho, el propio Camacho subraya que una de las características fundamentales de sus primeros profesores era la insistencia en someter todas las experiencias, informaciones, aseveraciones y lecturas a "la implacable crítica de la confirmación empírica”. La Facultad de Sociología de la Universidad Nacional representaba de hecho, en el contexto cultural colombiano del momento, una subversión del catolicismo, el dogmatismo y el escolasticismo, que dominaba a amplios sectores del establecimiento. Y esa subversión estaba representada, no tanto por un marxismo crítico, sino por un "positivismo, laico y secular", que impulsaba el trabajo empírico como su principal herramienta. En síntesis, pues, la subversión estaba compuesta por una mezcla compleja de marxismo ortodoxo, positivismo y funcionalismo, con todas las contradicciones y las inconsecuencias que de allí se pueden derivar.

Estas experiencias lo llevan entonces a la comprensión de que donde había sociología había pensamiento crítico, siempre y cuando fuera posible en cada caso particular recuperar el proyecto de la artesanía intelectual, es decir, la concepción de la sociología como un oficio, que había aprendido en la lectura de Wright Mills, uno de sus grandes maestros. La dimensión crítica de la sociología pasaba por esta dimensión empírica y era la que permitía encontrar un punto positivo de referencia común, que superara tanto la "metafísica" del funcionalismo como el dogmatismo del marxismo, así como Mills había encontrado en la "artesanía intelectual" el punto de referencia que le permitía escapar a la oposición entre los "abismos insondables" de la "gran teoría" y el "empirismo abstracto". El carácter subversivo de la sociología provenía entonces de que se considerara el ejercicio de esta profesión como un oficio orientado a la investigación empírica. El sociólogo era, pues, un intelectual artesano, consciente y crítico.

La idea de "sociología crítica", fundada en un trabajo artesanal, también tenía un fundamento de carácter más general. En sus clases de los años 1970, los estudiantes aprendíamos que el pensamiento de Marx se caracterizaba por su énfasis en el carácter social y en la especificidad histórica de todo fenómeno perteneciente al mundo de la sociedad. Estas dos perspectivas eran consideradas como el punto de partida de una crítica de las ideologías alrededor de las cuales se constituye no solo el capitalismo en particular, sino la sociedad moderna en su conjunto, ya que las relaciones sociales actuales se presentan como eternas y el individuo aparece como un ser autónomo desligado de los lazos comunitarios. Al llevar a cabo la crítica de estos "mitos modernos", la sociología establece un vínculo indisoluble entre teoría y acción, y el trabajo del sociólogo adquiere sentido precisamente por la contribución a su puesta en cuestión. Y estas dos ideas, que parecían tan originales del marxismo, eran al mismo tiempo la premisa fundamental de cualquier tipo de sociología (marxista o no marxista) que pretendiera constituirse como tal, siempre y cuando se inscribiera en parámetros concretos de espacio y tiempo.

El carácter subversivo de la sociología también proviene para Camacho del hecho de ser una disciplina que hace parte del "proceso de pensarnos como sociedad", como "una realidad independiente del capital, del Estado, de la religión" y de cualquier otra institución que tenga la pretensión de imponer "normas 
de conducta alienantes", según su propia expresión. La labor fundamental del sociólogo sería entonces actuar sobre la sociedad para que esta se convierta en sujeto por sí misma. Toda sociedad lucha de manera permanente por el logro de una identidad y la sociología tiene sentido precisamente en la medida en que sirve de estímulo para lograr ese objetivo y para favorecer procesos de movilización colectiva que conduzcan a una "participación deliberante, consciente y masiva", que haga posible que los que no tengan voz puedan asumirla. La mirada sociológica se convierte así en la posibilidad de proponer perspectivas políticas de nuevo tipo. Si la sociología se compromete con la modernización, con el cambio social, con el impulso a una democracia participativa e incluyente, con la promoción de reformas sociales, y con la crítica a los mitos colectivos, se convierte en una "actividad subversiva peligrosa". Y para ello el instrumento adecuado es precisamente la realización de trabajos empíricos, que permitan develar el verdadero sentido de la relaciones sociales, que de por sí no son puras ni transparentes.

Todo este ideario se puede expresar en sus propias palabras: "Tenemos que entender que un Estado fuerte sin una sociedad fuerte puede ser el reino del autoritarismo y que una sociedad débil sin Estado de derecho puede ser el de la barbarie. Y entender esto y trabajar ante todo por una sociedad fuerte, que pueda controlar a su propio Estado de derecho, es construir las condiciones de posibilidad de nuestro oficio, es decir, es hacernos sociólogos" ${ }^{4}$. Y desde este punto de vista teoría y práctica se presentan entonces como elementos indisolubles en el ejercicio de la sociología. Esta es la concepción de esta disciplina que nos presenta en el discurso de despedida de la Universidad del Valle de 1991 y la que le da sentido a la recopilación de textos que aparecen en la Obra selecta. El imperativo básico de la actividad intelectual y política de Camacho es hacer sociología crítica, entendida como sociología empírica.

\section{La persona}

Parte fundamental de la obra de Camacho fue su propia vida, la que compartió con sus amigos, la que sobrevive en el recuerdo de los que estuvimos cerca como colegas o como estudiantes. Como dijo Gonzalo Sánchez el día del funeral, "de Álvaro sabemos lo que podemos contar todos sus amigos", porque "su vida era la de los demás". Como anexo del primer volumen de su Obra selecta aparece una sección que recoge los testimonios presentados por sus amigos en el momento de su muerte donde encontramos preciosos comentarios sobre sus realizaciones y su personalidad, con la convicción de que nada hay más importante que permanecer en la memoria de los amigos, de aquellos con los que se vive y se lucha.

En el liderazgo de procesos académicos la diferencia entre lo personal y lo profesional tendía a diluirse y las características de su propia personalidad se convertían en un "instrumento de trabajo" para la realización de sus proyectos. Los amigos lo recuerdan con mucho afecto, como un hombre leal, generoso y 
solidario y como un gran colaborador en sus labores intelectuales; como una persona que estimulaba la investigación y el trabajo académico, abría senderos de reflexión y estaba produciendo todos los días, de manera infatigable, ideas y proyectos nuevos. Se tomaba el trabajo de leer las cosas que uno escribía y devolvía los textos que se le encomendaban con prolijos comentarios escritos a mano que demostraban con creces su compromiso con la tarea.

Su orientación intelectual era muy próxima a una dimensión artística y su principal obra de arte, más que sus textos, era su propia personalidad, marcada por un gran histrionismo y por un intento de hacer en su vida y en sus relaciones personales una dramaturgia permanente, a la altura del mejor artista y comediante. Tenía un "humor negro", corrosivo, subversivo y demoledor por el cual pasaban toda clase de personajes, cercanos o lejanos, sobre todo los que se afirmaban desde una posición de poder. La relación con él no era fácil por el hecho de ser obsesivo con su trabajo y estar reclamando siempre de sus pares o de sus alumnos que generaran iniciativas, asumieran responsabilidades y produjeran resultados. Pero en los momentos más difíciles, cuando se presentaban discrepancias o conflictos, siempre aparecía el humor como el punto de referencia para moderar cualquier tipo de dificultad y como el espacio que permitía restaurar el vínculo. Muchos de sus amigos utilizan la palabra gruñón para referirse a sus intervenciones. Uno de ellos, Nicolás Rodríguez, dice que "gruñía las ideas" y regañaba porque ese era su lenguaje y una de sus formas privilegiadas de comunicación. Pero mientras regañaba, agrega Nicolás, "los demás reíamos". Tenía una inmensa capacidad narrativa, sus intervenciones estaban repletas de anécdotas y referencias a sucesos y era un cultor de aquello que Montaigne llamaba el "arte de la conversación". Mantuvo siempre un interés por la cultura. Releía con mucha frecuencia El Quijote y en todo momento tenía entre manos la lectura de alguna obra literaria, a diferencia de lo que ocurre con muchos de nuestros académicos.

Los que fuimos alumnos suyos en la Universidad lo recordamos con mucho cariño, sobre todo por la forma agradable y amena como se desarrollaban sus clases, en las que desplegaba plenamente todo el sentido de humor que poseía y una gran irreverencia frente a la vanidad y a la ostentosidad ridícula de todo lo que apareciera como símbolo de poder. ¿Quién no recuerda la referencia a los demiurgos, la historia del "lecho de Procusto", el "crujir de dientes" y el "desgarre de las vestiduras" como metáforas recurrentes en su enseñanza? En su versión de María, la de Jorge Isaac, no había muerto de tuberculosis sino como consecuencia del desarrollo del capitalismo, que al transformar las idílicas relaciones patriarcales de la hacienda esclavista, se la había llevado inexorablemente a la tumba, al cambiar su entorno económico y social. Referencias de este estilo eran frecuentes en sus intervenciones. Sus clases, más que conferencias magistrales, eran la "puesta en escena" de una idea, con base en toda clase de recursos teatrales.

Freud dice en alguna parte que los maestros no nos seducen tanto por la doctrina que nos enseñan como por algún rasgo personal que identificamos en ellos, que coincide de alguna manera con la historia y los proyectos propios, así no sepamos dar cuenta de ellos conscientemente. En los años 1970 llegaba a la Universidad del Valle montado en un viejo Volkswagen, se dejaba la barba, vestía 
con camisas indígenas y utilizaba sandalias, a pesar de que todo en él delataba la pertenencia a una etnia blanca y a una familia relativamente burguesa. Su actitud intelectual y personal era la de un hombre contestatario de sus orígenes y crítico de las condiciones sociales, económicas y políticas del país. Su apariencia era la de un burgués culto pero rebelde, amante de la buena vida pero militante de izquierda, y perteneciente a una familia comprometida con actividades artísticas. Todos estos rasgos hacían parte de un inmenso trabajo de seducción en favor de la investigación y la cultura y contribuían a fomentar en nosotros, sus estudiantes de entonces, el interés por la sociología. No sé si al salir de las clases habíamos aprendido mucho en estricto sentido, conceptualmente hablando, pero lo que sí ocurría siempre es que quedábamos convencidos de que aquello de lo que Camacho hablaba era importante y debíamos a toda costa interesarnos por esos temas. El maestro, más que un saber, lo que debe comunicar a los estudiantes es un entusiasmo, decía Estanislao Zuleta. Y eso era precisamente lo que hacía Álvaro Camacho.

Alberto Valencia Gutiérrez ${ }^{5}$

Profesor e investigador de la Universidad del Valle, Cali Colombia alberto.valencia@correounivalle.edu.co

5 Doctor en Sociología. Editor general de la Obra selecta del profesor Álvaro Camacho. Bogotá-Cali: Universidad de los Andes, Universidad del Valle, 2014. 